OPEN ACCESS

Edited by:

Calvin S. Kalman,

Concordia University, Canada

Reviewed by:

Elizabeth S. Charles,

Dawson College, Canada

Juss Kaur Magon,

McGill University, Canada

*Correspondence:

Stella Vosniadou

stella.vosniadou@flinders.edu.au

Specialty section:

This article was submitted to

STEM Education,

a section of the journal

Frontiers in Education

Received: 11 February 2019

Accepted: 27 March 2019

Published: 16 April 2019

Citation:

Vosniadou S (2019) The Development

of Students' Understanding of

Science. Front. Educ. 4:32 doi: 10.3389/feduc.2019.00032

\section{The Development of Students' Understanding of Science}

\author{
Stella Vosniadou* \\ College of Education, Psychology and Social Work, Flinders University, Adelaide, SA, Australia
}

Children construct intuitive understandings of the physical world based on their everyday experiences. These intuitive understandings are organized in skeletal conceptual structures known as framework theories. Framework theories are different from currently accepted science and impose constraints on how students understand the scientific explanations of phenomena causing the creation of fragmented or synthetic conceptions. It is argued that in order to understand science students need to make important changes in the way they represent and explain the physical world as well as in their ways of reasoning. During the development of science knowledge students must also create new concepts and new belief systems which do not necessarily supplant their framework theories but co-exist with them. These developments are gradual and slow and follow a learning progression. In order to be effective science education needs to make students aware of their intuitive understandings, provide scientific information gradually and in agreement with students' learning progressions and develop students' reasoning abilities and executive function skills.

Keywords: science education, misconceptions, intuitive theories, conceptual change, cognitive conflict

In the last 50 or so years, research in science education has provided a great deal of information about how students develop an understanding of science concepts. In the pages that follow I will focus on three aspects of this development: the creation of intuitive understandings, the process of science learning, and the presence of conceptual co-existence. I will then discuss their implications for science education.

\section{INTUITIVE UNDERSTANDINGS}

Students are not blank slates when they are first exposed to the learning of science. On the contrary they bring to the science learning task intuitive understandings of the physical world, which can be very different from the scientific concepts and theories presented in the science classroom (Driver and Easley, 1978; Clement, 1982; McCloskey, 1983; Novak, 1987). Researchers agree on the presence of these intuitive understandings, but disagree when they try to describe their nature. There are three main points of view on this matter. The first, known as the classical approach, claims that students conceptions have the status of unitary intuitive theories, often resembling earlier theories in the history of science. The second approach, known as "knowledge-in-pieces, claims that students" conceptions consist of a multiplicity of phenomenological principles or p-prims, which are abstracted from experiential knowledge. According to the third approach, known 
as framework theory, students' conceptions consist of a collection of beliefs and presuppositions, which are organized in loose but relatively coherent framework theories.

There is some evidence to support the claim that students' conceptions represent relatively stable and deeply held intuitive theories. For example, McCloskey (1983) showed that there are systematic beliefs about the motion of objects that influence people's interactions with objects in the real world. These systematic beliefs are at variance from Newtonian mechanics and resemble a medieval theory of motion known as impetus theory. According to the impetus theory the motion of an object is maintained by a force internal to the object (impetus) which was acquired when the object was originally set in motion (McCloskey, 1983).

However, not all of students' conceptions can be characterized as unitary and systematic intuitive theories. According to Chi (2013), in addition to false intuitive theories, people also have false beliefs and false mental models. There are also constraints on students' ways of reasoning, such as constraints on the nature of causal explanations, which can give rise to misinterpretations of scientific information. For example, people often rely on a generalized version of a Direct-Causal schema to produce misconceived causal explanations for emergent processes, such as diffusion, natural selection, and heat transfer for which a direct-causal schema does not apply (Chi et al., 2012). Emergent processes do not have a single identifiable causal agent or an identifiable sequence of stages. On the contrary, they result from the simultaneous interactions of all agents.

At the opposite end of the intuitive theory position is the claim that students' initial understandings consist of knowledgein-pieces (diSessa, 1993). diSessa has provided evidence from extensive interviews with students to support the position that students do not hold systematic and unitary intuitive theories but are internally inconsistent and fragmented and that their knowledge fragments can best be characterized in terms of p-prims. The "knowledge-in-pieces" position can account for the inconsistencies often observed in students' explanations, especially when the students are asked to explain the same physical phenomena in different situational contexts. It is problematic, however, when it comes to interpreting students' more complex, theory-like constructions which have been found to be resistant to instruction such as the intuitive theories discussed earlier (Clement, 1982). It also cannot explain constraints on students' causal explanations such as the ones described by Chi (2013), which can give rise to erroneous interpretation of scientific information.

Both the "intuitive theory" and the "knowledge-in-pieces" positions are based on empirical evidence coming from interviews with secondary school or University students and lay adults. In contrast, Vosniadou and her colleagues (Vosniadou and Brewer, 1992, 1994; Vosniadou, 2013; Vosniadou and Skopeliti, 2017) have argued that it is important to make a distinction between students' conceptions formed before exposure to science instruction and after being exposed to science. They have used empirical evidence from interviews with young children before they were exposed to science instruction to argue that children interpret their everyday experiences in the context of lay culture to form beliefs, which are organized in loose but relatively coherent framework theories (Vosniadou, 2013; Vosniadou and Skopeliti, 2014).

A framework theory is different from an intuitive theory. An intuitive theory is a cohesive, unitary theory, which might contain misconceptions of scientific information. On the contrary, a framework theory is considered to be a skeletal conceptual system that grounds our most fundamental ontological categorizations and causal devices in terms of which we understand the world and on the basis of which new information is built, before any exposure to science (Wellman and Gelman, 1998). A framework theory lacks the systematicity, consistency, and explanatory power of scientific theories and it is not explicit and socially shared. It is however a principle-based system with learning mechanisms, such as categorization and causal attribution, capable of giving rise to explanation of phenomena and prediction (Gopnik et al., 2001; Slousky, 2003). For example, infants make an ontological distinction between objects with or without self-initiated movement (animate vs. inanimate). This distinction can then be used productively to categorize new, previously unseen, objects and attribute to them characteristics of animate or inanimate objects, such as solidity, need for support and the presence or absence of intentionality (Vosniadou and Brewer, 1992, 1994).

The framework theory approach (Vosniadou, 2013) does not exclude the possibility that knowledge elements such as pprims might be present in our knowledge system. However, they are considered to be organized in loose conceptual structures from early on in childhood. Take for example the well-known Ohm's p-prim-that more effort leads to more effect and more resistance leads to less effect (diSessa, 1993). Although the Ohm's p-prim might serve to schematize a phenomenological experience, it can only be formulated in a conceptual system in which a distinction has already been made between animate and inanimate objects and in which it is already known that effort is usually exerted by the pull or push of animate agents, that forces are implicated, and that the size and weight of the agents and of the objects in question are important (Ioannides and Vosniadou, 2002). In other words, the very generation of an explanatory principle such as a p-prim already presupposes the presence of a skeletal conceptual system, such as a framework theory. Indeed, for researchers who employ a complex systems approach to science learning (e.g., Brown and Hammer, 2008, 2013), also advocated by diSessa (1993), the creation of integrative conceptual structures such as framework theories is not inconsistent with the knowledge-in-pieces approach.

\section{THE PROCESS OF SCIENCE LEARNING}

The position one takes regarding the nature of students' intuitive understandings can have important implications about how one interprets the process of science learning. If students' conceptions have the form of intuitive theories then the process of science learning cannot be seen as one of accretion or enrichment of prior knowledge. What is needed is instead theory change, or otherwise known, conceptual change. Posner et al. (1982) argued 
that conceptual change requires the replacement of intuitive theories with the correct scientific ones. This replacement was described as the result of a rational process during which students need to become aware of the fundamental assumptions and epistemological commitments that characterize their intuitive theories and to realize their limitations and inadequacies vis. a vis. the scientific theory.

In the years that followed, the so called "classical approach" became subject to a number of criticisms. One issue of contention was the proposal that intuitive understandings are replaced by scientific theories. Arguments regarding the co-existence of intuitive understandings and scientific concepts were put forward early on (e.g., Caravita and Halldén, 1994) but became supported by empirical evidence in recent years and will be discussed in greater detail later.

Contrary to the sudden theory replacement via cognitive conflict view of science learning, the knowledge-in-pieces approach promoted the idea that the process of science learning should be seen as one of conceptual integration, during which the multiplicity of p-prims become organized into coherent scientific theories under the influence of instruction (diSessa, 1993, 2008). Smith et al. (1993) argued that cognitive conflict is not a good instructional strategy because it is inconsistent with a constructivist approach to learning; namely that learning is a process of building new knowledge on what we already know. They proposed instead that intuitive understandings are productive ideas that can serve as resources for science learning, and which evolve and become integrated in cohesive conceptual structures such as scientific theories through appropriate instruction. The emphasis on integration and discrimination rather than on confrontation and cognitive conflict is the hallmark of the knowledge-in-pieces approach to instruction (see also Clark and Linn, 2008).

I will support a different view of science learning, one consistent with the framework theory approach. According to this view students organize their intuitive understandings in loose and narrow but nevertheless relatively cohesive framework theories before they are exposed to science instruction. Framework theories are fundamentally different from scientific theories in their explanations, in their concepts, and in their ontological and epistemological presuppositions. When students who operate with an understanding of the physical world such as the one described as a framework theory of physics are first exposed to an incompatible and counter-intuitive scientific theory, they are not capable of understanding it. Assuming that these students use constructive learning mechanisms they will interpret the new scientific information in light of their prior knowledge. This constructive process will almost necessarily result in the creation of misconceptions which are hybrids-i.e., conceptions that have elements both of intuitive understandings and of scientific information. In a text comprehension study that tested the above proposition directly, Vosniadou and Skopeliti (2017) showed that many elementary school students who gave intuitive explanations of the day/night cycle at pretest either ignored the scientific information altogether, or created misconceptions when exposed to the counter-intuitive scientific explanation. These misconceptions were hybrids that could be distinguished into fragmented and/or synthetic conceptions. A fragmented conception is one that combines intuitive understandings with scientific information without concern for internal consistency or explanatory power (e.g., day/night happens because the sun goes behind the mountains and also because the earth "moves"). A synthetic conception also combines intuitive understandings with scientific information but does so in ways that show some concern for internal consistency and explanatory power. Vosniadou and Skopeliti (2017) concluded that science learning is not produced through sudden insights but it is a slow and gradual process and that the generation of misconceptions is a natural outcome of this process. In other words, many misconceptions are not accidental errors but fragmented or synthetic conceptions produced when students use constructive learning mechanisms that connect incompatible scientific information with their prior knowledge.

\section{CO-EXISTENCE OF INTUITIVE UNDERSTANDINGS AND SCIENTIFIC CONCEPTS}

Recent research has shown that intuitive understandings are not completely replaced by scientific theories, not even in expert scientists. Rather, intuitive understandings co-exist with scientific concepts and may interfere with their access in scientific reasoning tasks. For example, Kelemen et al. (2013) showed that when tested under the pressure of time, with information processing capacity taxed, even expert scientists were likely to endorse non-scientific, teleological explanations of phenomena. In another study, Shtulman and Valcarel (2012) showed that college-educated adults were less accurate and slower to verify scientific concepts that were inconsistent compared to those that were consistent with naïve theories, suggesting that naïve theories continue to exist and interfere in the processing of scientific theories (see also Babai et al., 2010; Potvin et al., 2015).

Masson et al. (2014) used functional magnetic resonance imaging (fMRI) to compare brain activation in experts and novices when evaluating the correctness of simple electric circuits. Their results showed that experts, more than novices, activated brain areas involved in inhibition when evaluating nonscientific circuits, presumably because they were suppressing misconceptions encoded in their brain's neural networks.

The phenomenon of the co-existence of intuitive understandings and scientific concepts and theories raises important problems for theories of science learning and instruction as well as for theories of knowledge organization and representation. If earlier belief systems are not supplanted by information acquired later, how consistent is our knowledge base? How is it possible for the inconsistent old and new belief systems to co-exist, and for the inconsistencies not to be detected?

One way to explain the puzzle of the co-existence of intuitive understandings and scientific concepts is to see them not as incompatible representations organized within the same belief system, but as different belief systems encapsulated in overlapping but partly distinct neural networks within particular 
domains of knowledge (Vosniadou, in press). This view is more consistent with the results of cognitive neuroscience research, which show that conceptual knowledge is represented in distributed networks located in different parts of the adult brain (Allan et al., 2014; Fugelsang and Mareschal, 2014). In such a system, coherence is not an attribute of the organization of information in the knowledge base but the outcome of an effective executive function system capable of selecting, integrating, or inhibiting information from different belief systems in ways that are appropriate for the task at hand.

The role of executive function and its relation to academic learning and conceptual change has become an important area of research in recent years. Executive function is a set of neurocognitive skills, such as working memory, cognitive flexibility, and inhibitory control. These skills are fundamental for engaging in goal-directed thought and action and for learning, particularly the learning of counter-intuitive concepts in science and mathematics. Research has shown that executive function skills are significantly related to academic achievement and to conceptual change learning, even when intelligence and prior knowledge are controlled for (Allan et al., 2014; Fugelsang and Mareschal, 2014; Vosniadou et al., 2018). The learning of science and mathematics concepts that are inconsistent with intuitive understandings has been associated specifically with the executive function skill of inhibitory control (see also Zaitchick et al., 2014; Carey et al., 2015).

\section{IMPLICATIONS FOR TEACHER EDUCATION AND PROFESSIONAL DEVELOPMENT}

Different theoretical approaches to science learning have proposed different recommendations for science instruction. The classical approach (Posner et al., 1982) considered cognitive conflict as the main instructional strategy for science learning. Cognitive conflict works by presenting the learner with conflicting evidence. This conflicting evidence is designed to produce dissatisfaction with the learners' intuitive theory and the recognition that it needs to be replaced by the scientific theory. One of the problems with instructional uses of cognitive conflict is that it does not guarantee that learners will experience the intended external conflict as internal cognitive dissonance. Chinn and Brewer (1993) have presented persuasive arguments that indicate that learners can respond to conflicting evidence in different ways. Indeed, many students and teachers hold inconsistent beliefs without being seemingly aware of the inconsistencies.

Contrary to what is known as the classical approach, the "knowledge-in-pieces" (diSessa, 1993) approach emphasizes the integration of students' p-prims into coherent scientific theories. This approach is based on the assumption that p-prims are productive and that what is needed is to find a way to integrate them into internally-consistent scientific theories. It does not, however, tell us what to do with intuitive understandings that might not be productive when it comes to learning a scientific theory.
From the perspective of the framework theory there are three main points that need to be emphasized regarding instruction. First, science learning is a constructive process that gradually builds on and modifies prior knowledge. Depending on the learners' prior knowledge, learning the correct scientific explanation is not something that happens immediately and suddenly; rather, it may take some time to be accomplishedthere is a learning progression involved (Vosniadou and Brewer, 1992, 1994; Wiser and Smith, 2008; Vosniadou and Skopeliti, 2017, 2018). Indeed the whole idea of building learning progressions is to capture the intermediate steps in the learning of science concepts and theories (Corcoran et al., 2009; Duschl et al., 2011). When science educators are aware of the students' learning progression in a given subject matter area, they can provide scientific information that is less likely to be misunderstood.

Second, cognitive conflict can be used in the process of learning science but mainly in order to increase students' metacognitive awareness and understanding of the gap between their existing beliefs and the new scientific information rather than to prove that intuitive understandings are wrong and need to be replaced. Intuitive understandings are resistant to instruction because they are immediate and common-sense interpretations of everyday experience and because they are constantly reinforced by this experience. On the contrary, scientific concepts are usually not supported by everyday experience and require the construction of new, abstract, and complex representations that do not have a one-toone correspondence to the things they represent. Students need to be facilitated to create these new, counter-intuitive representations, understand that they are based on different, non-egocentric perspectives and that they have much greater explanatory power.

Last but not least science instruction needs to develop students' reasoning abilities, their epistemological beliefs and their executive function skills. Science learning requires complex spatial reasoning, the ability to take different perspectives, construct complex and abstract models and representations and inhibit prior knowledge so that new, conflicting information can be entertained. The cultivation of these skills and ways of reasoning should be an integral part of science instruction.

\section{CONCLUSIONS}

It has been argued that children start the knowledge acquisition process by forming beliefs based on their everyday experiences and lay culture. These beliefs are not isolated but organized in loose and narrow but relatively coherent framework theories. Although framework theories are implicit, not socially shared and lack the systematicity and explanatory power of scientific theories, they are principle-based systems with learning mechanisms such as categorization and causal attribution that can give rise to explanation and prediction. Scientific concepts and theories are very different in their concepts, organization, ontological and epistemological presuppositions and in their representations from framework theories. They require major conceptual changes to take place in order to be 
fully understood. These conceptual changes take time to be accomplished. The development of science knowledge is a long and gradual process during which students use constructive learning mechanisms to assimilate new, scientific, information into their prior knowledge causing hybrid conceptions-or misconceptions. Science instruction needs to help students become aware of their experience-based beliefs that might constrain science learning causing misconceptions, provide

\section{REFERENCES}

Allan, N. P., Hume, L. E., Allan, D. M., Farrington, A. L., and Lonigan, C. J. (2014). Relations between inhibitory control and the development of academic skills in preschool and kindergarten: a meta-analysis. Dev. Psychol. 50, 2368-2379. doi: $10.1037 / \mathrm{a} 0037493$

Babai, R., Sekal, R., and Stavy, R. (2010). Persistance of the intuitive conception of living things in adolescence. J. Sci. Educ. Technol. 19, 20-26. doi: 10.1007/s10956-009-9174-2

Brown, D., and Hammer, D. (2013). "Conceptual change in physics," in International Handbook of Research on Conceptual Change, 2nd Edn, ed S. Vosniadou (New York, NY: Routledge), 121-137.

Brown, D. E., and Hammer, D. (2008). "Conceptual change in physics," in International Handbook of Research on Conceptual Change, ed S. Vosniadou (New York, NY: Routledge), 121-137.

Caravita, S., and Halldén, O. (1994). Re-framing the problem of conceptual change. Learn. Instr. 4, 89-111. doi: 10.1016/0959-4752(94)90020-5

Carey, S., Zaitchik, D., and Bascandziev, I. (2015). Theories of development: in dialog with Jean Piaget. Dev. Rev. 38, 36-54. doi: 10.1016/j.dr.2015. 07.003

Chi, M. (2013). "Two kinds and four sub types of misconceived knowledge, ways to change it and the learning outcomes," in International Handbook of Research on Conceptual Change, 2nd Edn, ed S. Vosniadou (New York, NY: Routledge), 49-71.

Chi, M. T. H., Roscoe, R., Slotta, J., Roy, M., and Chase, C. C. (2012). Misconceived causal explanations for emergent processes. Cogn. Sci. 36, 1-61. doi: 10.1111/j.1551-6709.2011.01207.x

Chinn, C. A., and Brewer, W. (1993). The role of anomalous data in knowledge acquisition: a theoretical framework and implications for science instruction. Rev. Educ. Res. 63, 1-49. doi: 10.3102/00346543063001001

Clark, D. B., and Linn, M. C. (2008). "The knowledge integration perspective: connections across research and education," in International Handbook of Research on Conceptual Change, ed S. Vosniadou (New York, NY: Routledge), 520-559.

Clement, J. (1982). Students' preconceptions in introductory mechanics. Am. J. Phys. 50, 66-70.

Corcoran, T., Mosher, F. A., and Rogat, A. (2009). Learning Progressions in Science. An Evidence-Based Approach to Reform. Consortium for Policy Research in Education Report \#RR-63. Philadelphia, PA: Consortium for Policy Research.

diSessa, A. (1993). Towards an epistemology of physics. Cogn. Instr. 10, 105-225. doi: 10.1080/07370008.1985.9649008

diSessa, A. A. (2008). “A bird's-eye view of the 'pieces' vs 'coherence' controversy (from the pieces side of the fence)," in International Handbook of Research on Conceptual Change, ed S. Vosniadou (New York, NY: Routledge), 35-60.

Driver, R., and Easley, J. (1978). Pupils and paradigms: a review of literature related to concept development in adolescent science students. Stud. Sci. Educ. 5, 61-84. doi: 10.1080/03057267808559857

Duschl, R., Maeng, S., and Sezen, A. (2011). Learning progessions and teaching sequences: a review and analysis. Stud. Sci. Educ. 47, 123-182. doi: 10.1080/03057267.2011.604476

Fugelsang, J., and Mareschal, D. (2014). "The development and application of scientific reasoning," in Educational Neuroscience, eds D. Mareschal, B. Butterworth, and A. Tolmie (Chichester: Wiley-Blackwell), 237-267.

Gopnik, A., Sobel, D. M., Schulz, L., and Glymour, C. (2001). Causal learning mechanisms in very young children: two-, three-, and four-year-olds infer information gradually based on students' learning progressions and develop students' scientific reasoning and executive function skills.

\section{AUTHOR CONTRIBUTIONS}

The author confirms being the sole contributor of this work and has approved it for publication.

causal relations from patterns of variation and covariation. Dev. Psychol. 37, 620-629. doi: 10.1037//0012-1649.375.620

Ioannides, C., and Vosniadou, S. (2002). The changing meanings of force. Cogn. Sci. Quart. 2, 5-62.

Kelemen, D., Rottman, J., and Seston, R. (2013). Professional physical scientists display tenacious teleological tendencies: purpose-based reasoning as a cognitive default. J. Exp. Psychol. Gen. 142, 1074-1083. doi: 10.1037/a0030399

Masson, S., Potvin, P., Riopel, M., and Brault-Foisy, L.-M. (2014). Differences in brain activation between novices and experts in science during a task involving a common misconception in electricity. Mind Brain Educ. 8, 44-55. doi: $10.1111 / \mathrm{mbe} .12043$

McCloskey, M. (1983). Intuitive physics. Sci. Am. 248, 122-130. doi: 10.1038/scientificamerican0483-122

Novak, J. D. (1987). "Introduction," in Proceedings of the Second International Seminar: Misconceptions and Educational Strategies in Science and Mathematics (Ithaca, NY; New York, NY: Cornell University).

Posner, G. J., Strike, K. A., Hewson, P. W., and Gertzog, W. A. (1982). Accommodation of a scientific conception: towards a theory of conceptual change. Sci. Educ. 66, 211-227. doi: 10.1002/sce.3730660207

Potvin, P., Masson, S., Lafortune, S., and Cyr, G. (2015). Persistence of the intuitive conception that heavier objects sink more: a reaction time study with different levels of interference. Int. J. Sci. Mathem. Educ. 13, 21-34. doi: 10.1007/s10763-014-9520-6

Shtulman, A., and Valcarel, J. (2012). Scientific knowledge suppresses but does not supplant earlier intuitions. Cognition 124, 209-215. doi: 10.1016/j.cognition.2012.04.005

Slousky, V. M. (2003). The role of similarity in the development of categorization. Trends Cogn. Sci. 7, 246-251. doi: 10.1016/S1364-6613(03)00109-8

Smith, J. P., diSessa, A. A., and Rochelle, J. (1993). Misconceptions reconceived: a constructivist analysis of knowledge in transition. J. Learn. Sci. 3, 115-163. doi: 10.1207/s15327809jls0302_1

Vosniadou, S. (2013). "Conceptual change in learning and instruction: the framework theory approach," in The International Handbook of Conceptual Change, 2nd Edn, ed S. Vosniadou (New York, NY: Routledge), 11-30.

Vosniadou, S. (in press). "Teachers' beliefs and knowledge," in Problem Solving in Learning and Teaching: A Festschrift for Emeritus Professor Mike Lawson, eds J. Orrell and H. Askell-Williams.

Vosniadou, S., and Brewer, W. F. (1992). Mental models of the earth. Cogn. Psychol. 24, 535-585. doi: 10.1016/0010-0285(92)90018-W

Vosniadou, S., and Brewer, W. F. (1994). Mental models of the day/night cycle. Cogn. Sci. 18, 123-183. doi: 10.1207/s15516709cog1801_4

Vosniadou, S., Pnevmatikos, D., and Makris, N. (2018). The role of executive function in the construction and employment of science and mathematics concepts that require conceptual change learning. Neuroeducation 5, 58-68. doi: 10.240.46/neuroed.20180502.58

Vosniadou, S., and Skopeliti (2017). Is it the Earth that turns or the Sun that goes behind the mountains? Students' misconceptions about the day/night cycle after reading a science text. Int. J. Sci. Educ. 39, 2027-2051. doi: 10.1080/09500693.2017.1361557

Vosniadou, S., and Skopeliti, E. (2018). Evaluating the effects of analogy enriched text on the learning of science. The importance of learning indexes. J. Res. Sci. Teach. doi: 10.1002/tea.21523. [Epub ahead of print].

Vosniadou, S., and Skopeliti, I. (2014). Conceptual change from the framework theory side of the fence. Sci. Educ. 23, 1427-1445. doi: $10.1007 /$ s11191-013-9640-3 
Wellman, H. M., and Gelman, S. A. (1998). "Knowledge acquisition in foundational domains," in Cognition, Perception and Language. Volume 2 of the Handbook of Child Psychology, 5th Edn, eds D. Kuhn and R. Siegler (New York, NY: Wiley), 523-573.

Wiser, M., and Smith, C. L. (2008). "Learning and teaching about matter in grades K-8: when should the atomic-molecular theory be introduced?," in International Handbook of Research on Conceptual Change, ed S.Vosniadou (New York, NY: Routledge), 205-239.

Zaitchick, D., Iqbal, Y., and Carey, S. (2014). The effect of executive function on biological reasoning in young children: an individual differences study. Child Dev. 85, 160-175. doi: 10.1111/cdev.12145
Conflict of Interest Statement: The author declares that the research was conducted in the absence of any commercial or financial relationships that could be construed as a potential conflict of interest.

Copyright (c) 2019 Vosniadou. This is an open-access article distributed under the terms of the Creative Commons Attribution License (CC BY). The use, distribution or reproduction in other forums is permitted, provided the original author(s) and the copyright owner(s) are credited and that the original publication in this journal is cited, in accordance with accepted academic practice. No use, distribution or reproduction is permitted which does not comply with these terms. 